\title{
PENENTUAN UMUR SIMPAN BAKSO WARNA IKAN LELE (Clarias $\mathrm{Sp)}$
}

\author{
Oleh \\ Tatty Yuniarti, Alvi Nur Yudhistira, Sujono \\ Dosen Sekolah Tinggi Perikanan Jurusan Penyuluhan Perikanan
}

\begin{abstract}
Abstrak
Penentuan umur simpan suatu produk makanan adalah penting diketahui untuk keamanan pangan konsumen. Bakso warna warni ikan lele yang diteliti adalah bakso warna merah dengan penambahan angkak. Bakso tersebut sebagai salah satu produk olahan ikan belum diketahui umur simpannya, sehingga perlu dilakukan penelitian. Penelitian bertujuan untuk penentukan umur simpan dari bakso warna ikan lele (Clarias Sp.). Penelitian menggunakan metoda percepatan Arrhenius. Dari hasil penelitian, atribut bau berupa ketengikan adalah atribut yang paling cepat mengalami perubahan dengan konsentrasi TBA sebesar $0,123 \mathrm{mg}$ malanoaldehid/kg sampel. Umur simpan bakso warna merah dapat ditentukan dengan menggunakan rumus $T s=6 \times 1,2333^{\delta T / 10}$. Bakso warna yang dikemas menggunakan plastik LDPE adalah 11,5 hari pada suhu $5{ }^{\circ} \mathrm{C}$ dengan metoda penentuan umur simpan Model Arrhenius.
\end{abstract}

Kata kunci: Clarias sp, bakso warna, umur simpan

\section{PENDAHULUAN}

Bakso ikan lele sebagai produk pangan mengalami deteriorasi segera setelah diproduksi. Reaksi deteriorasi dimulai dengan persentuhan produk dengan udara, oksigen, uap air, cahaya, mikroorganisme, atau akibat perubahan suhu. Reaksi ini dapat pula diawali oleh hentakan mekanis seperti vibrasi, kompresi, dan abrasi. Tingkat deteriorasi produk dipengaruhi oleh lamanya penyimpanan, sedangkan laju deteriorasi dipengaruhi oleh kondisi lingkungan penyimpanan. Umur simpan adalah waktu hingga produk mengalami suatu tingkat deteriorasi tertentu (Arpah dan Syarief 2000). Institute of Food Science and Technology (1974) di dalam Arpah dan Syarief (2000) mendefinisikan umur simpan produk pangan adalah selang waktu antara saat produksi hingga konsumsi di mana produk berada dalam kondisi yang memuaskan berdasarkan karakteristik penampakan, rasa, aroma, tekstur, dan nilai gizi.

Peraturan mengenai penentuan umur simpan bahan pangan telah dikeluarkan oleh Codex Allimentarius Commission (CAC) pada tahun 1985 tentang Food Labelling Regulation. Di Indonesia, peraturan mengenai penentuan umur simpan bahan pangan terdapat dalam UU Pangan No. 7 tahun 1996 dan PP No.69 tahun 1999. Terdapat tujuh jenis produk pangan yang tidak wajib mencantumkan tanggal, bulan, dan tahun kedaluwarsa, yaitu: buah dan sayuran segar, termasuk kentang yang belum dikupas, minuman yang mengandung alkohol lebih besar atau sama dengan $10 \%$ (volume/volume), makanan yang diproduksi untuk dikonsumsi saat itu juga atau tidak lebih dari 24 jam setelah diproduksi, cuka, garam meja, gula pasir, serta permen dan sejenisnya yang bahan bakunya hanya berupa gula ditambah flavor 
atau gula yang diberi pewarna. Berdasarkan peraturan, semua produk pangan wajib mencantumkan tanggal kedaluwarsa, kecuali tujuh jenis produk pangan tersebut.

Pendugaan umur simpan suatu produk
dapat dilakukan dengan metoda konvensional (extended storage studies/ESS) dan dengan percepatan (accelerated shelf life testing/ASLT) model Arrhenius. Prinsip penggunaan metoda konvensional adalah pendugaan umur simpan suatu produk pangan dengan menyimpan produk pada suhu normal (suhu, kelembaban udara) dan dilakukan pengamatan terhadap parameter penurunan mutu produk hingga tercapai tingkat mutu kadaluwarsa. Metoda ASLT model Arrhenius adalah pendugaan umur simpan suatu produk dengan mempercepat terjadinya penurunan mutu karena adanya pengaruh suhu (Syarief dan Halid 1993). Model konvensional dapat digunakan pada produk perikanan basah seperti fillet ikan dan burger ikan, sedangkan model Arrhenius dapat digunakan pada produk perikanan dalam kondisi basah, semi basah dan kering seperti udang beku dan dendeng ikan (Syuryanti dan Suryaningrum 2009).

Penelitian ini bertujuan untuk menentukan umur simpan bakso warna ikan lele menggunakan metoda Arrhenius. Manfaat dari penelitian ini adalah dapat ditentukan umur simpan produk sehingga dapat meningkatkan mutu dan keamanan pangan dalam rangka mengembangkan industrialisasi perikanan serta dapat membantu para penyuluh dalam menerapkan teknologi pendugaan umur simpan produk perikanan pada UMKM secara lebih cepat dan mudah.

\section{METODE PENELITIAN}

Penelitian dilakukan di Laboratorium Pasca Panen dan Laboratorium Kimia, Jurluhkan, Laboratorium Kimia Pangan, STP. Alat yang digunakan dalam penelitian ini adalah inkubator, freezer, food processor, cawan conway, oven, buret, pemanas listrik, glassware, spektrofotometer. Bahan yang diperlukan antara lain ikan lele, garam, bawang putih, merica, angkak.

Pada penelitian ini, hanya satu (1) jenis bakso warna yang akan ditentukan umur simpannya, yaitu bakso warna merah atau bakso dengan penambahan angkak sebagai pewarnanya (Yuniarti dkk 2011).

Penelitian pendahuluan dilakukan untuk mengetahui sifat kritis dari bakso warna ikan lele. Metoda yang digunakan adalah uji organoleptis metoda multiple comparison test dimana panelis diminta untuk membandingkan sampel 0 hari (kontrol) dengan sampel 0,2,4,6,dan 8 hari, dengan skore 1-6. Panelis yang digunakan adalah panelis terlatih sebanyak 15 orang (Meilgard 1999). Atribut sensori yang diamati adalah tekstur, bau, rasa dan kenampakan. Selanjutnya, ditentukan batas titik kritis menggunakan metoda triangle test, dalam pengujian ini panelis diminta untuk memilih satu diantara tiga sampel yang berbeda, misalnya sampel yang menunjukkan adanya bau tengik.

Penentuan perkembangan ketengikan bakso ikan lele warna berdasarkan angka TBA (SNI 2006). Analisa kimia tersebut dilakukan terhadap bakso ikan lele warna yang telah disimpan pada suhu 25, 35 dan $45{ }^{\circ} \mathrm{C}$ dalam plastik LDPE. Setiap perlakuan suhu terdiri dari enam (6) jenis perlakuan waktu bakso ikan, dan setiap analisa diambil satu jenis bakso. Analisa kimia dilakukan setiap 2 hari sekali untuk mengetahui kadar air dan angka TBA. Rancangan percobaan yang digunakan dalam penelitian ini adalah rancangan acak lengkap (RAL) faktor tunggal. Perlakuan dalam penelitian ini adalah waktu penyimpanan yaitu $0,2,4,6,8$ hari.

Pengujian perkembangan ketengikan bakso warna selama penyimpanan dilakukan dengan metode akselerasi model 
Arrhenius, dimana suhu merupakan faktor yang sangat berpengaruh terhadap perubahan mutu produk pangan. Akselerasi dilakukan pada suhu 25,35 , dan $45^{\circ} \mathrm{C}$ yang bertujuan untuk mempercepat tercapainya angka TBA kritis (Syarif dan Halid 1993).

\section{HASIL DAN PEMBAHASAN}

Berdasarkan uji organoleptis pada Tabel 1, parameter bau lebih cepat mengalami perubahan dibandingkan tekstur dan kenampakan, yaitu setelah bakso lele warna disimpan selama 6 hari. Parameter tekstur, dan kenampakan mengalami perubahan setelah bakso disimpan selama 8 hari. Dengan demikian parameter bau berupa ketengikan digunakan sebagai penentu sifat kritis bakso lele. Sifat kritis adalah sifat yang paling peka yang dapat dideteksi oleh konsumen untuk menolak suatu produk. Parameter ketengikan bakso lele ditentukan berdasarkan peningkatan angka TBA (thio-barbituric acid) selama waktu penyimpanan.

Tabel 1. Hasil uji organoleptis bakso warna pada suhu ruang $\left(27-30^{\circ} \mathrm{C}\right)$

\begin{tabular}{lccc}
\hline $\begin{array}{c}\text { Penyimpanan } \\
\text { (hari) }\end{array}$ & Tekstur & Bau & Penampakan \\
\hline 0 & $5,00 \mathrm{a}$ & $5,00 \mathrm{a}$ & $5,00 \mathrm{a}$ \\
2 & $5,02 \mathrm{a}$ & $5,05 \mathrm{a}$ & $5,01 \mathrm{a}$ \\
4 & $5,04 \mathrm{a}$ & $5,10 \mathrm{a}$ & $5,02 \mathrm{a}$ \\
6 & $5,09 \mathrm{a}$ & $5,25 \mathrm{~b}$ & $5,04 \mathrm{a}$ \\
8 & $5,15 \mathrm{~b}$ & $5,50 \mathrm{~b}$ & $5,06 \mathrm{a}$ \\
\hline
\end{tabular}

Kerusakan produk perikanan sering ditandai dengan timbulnya flavor tengik akibat dari reaksi oksidasi dan hidrolisis terhadap kandungan asam lemak tidak jenuh yang tinggi pada ikan. Reaksi ini menyebabkan terbentuknya senyawa radikal bebas dan bila berinteraksi dengan oksigen akan membentuk hidroperoksida yang bersifat tidak stabil dan akan terdegradasi lebih lanjut menghasilkan senyawa senyawa karbonil rantai pendek seperti aldehid dan keton yang bersifat volatil dan menimbulkan flavor tengik. Lemak juga mudah terhidrolisis dengan adanya air menjadi gliserol dan asam lemak. Tingkat kerusakan lemak dapat dideteksi melalui analisa free fatty acid (FFA), thiobarbituric acid (TBA), bilangan peroksida dan nilai anisidin (Syarief dan Halid 1993).

Penelitian sejenis yang menggunakan TBA sebagai parameter penentu umur simpan produk adalah produk udang beku (Tsironi dkk 2009), hot smoked fish dari ikan lele (Clarias gariepinus) (Yanar dkk 2008). Sedangkan Adoga dkk (2010) melakukan uji angka peroksida untuk menentukan perubahan lemak pada ikan segar African catfish (Clarias angullaris). Langraudi dkk (2011) menggunakan keduanya yaitu TBA dan angka peroksida (Peroksida Value=PV) untuk mendeteksi perubahan lemak pada ikan mas grass carp (Ctenopharyngodon idella). Selain ketengikan, tingkat kerusakan pangan dapat dideteksi menggunakan uji mikrobiologi seperti yang dilakukan oleh 
Adebayo-Tayo dkk (2012) pada pemeriksaan Fresh Catfish (Arius hendelotic). Azam dkk (2010) hanya menggunakan uji organoleptik untuk menentukan perubahan mutu udang (Penaeus monodon) yang diberi perlakuan dingin.

Pada penentuan tingkat kerusakan minyak yang dinyatakan dengan angka TBA (thio-barbituric acid), maka sampel pada hari ke- 6 menunjukkan hasil yang berbeda nyata dengan sampel kontrol (hari ke-0 dengan nilai TBA $0,123 \mathrm{mg}$ malanoaldehid $/ \mathrm{kg}$ sampel dalam berat kering. Uji organoleptik menggunakan panelis sebanyak 15 orang dan dibandingkan dengan hasil uji TBA, hasil selengkapnya disajikan pada Tabel 2.

Tabel 2. Penentuan tingkat ketengikan (bau) menggunakan uji organoleptik dan uji TBA

\begin{tabular}{ccccc}
\hline $\begin{array}{c}\text { Penyimpanan } \\
\text { (hari) }\end{array}$ & Benar & salah & tabel a 0,1 \% & $\begin{array}{c}\text { Angka TBA (mg } \\
\text { malonadehid/kg } \\
\text { sampel) }\end{array}$ \\
\hline 0 & 10 & 5 & 12 & 0,06 \\
2 & 10 & 5 & & 0,08 \\
4 & 11 & 4 & & 0,095 \\
$6^{*}$ & 13 & 2 & & 0,123 \\
$8^{*}$ & 14 & 1 & & 0,296 \\
\hline
\end{tabular}

Keterangan: "pada hari ke-6 dan hari ke-8 ,menunjukkan hasil yang berbeda nyata

Angka TBA pada bakso warna yang tidak diterima oleh panelis ini lebih rendah dari pada angka TBA dari ikan salmon (Salmo salar) yaitu sebesar $1.76 \pm 0.04 \mathrm{mg}$ melanoaldehid/kg bahan pada hari ke-18 penyimpanan beku, sedangkan pada hari ke-0 TBA ikan salmon tersebut adalah $0,29 \pm 0,04 \mathrm{mg}$ melanoaldehid $/ \mathrm{kg}$ bahan (Sauza dkk 2010). Nilai TBA sebesar 1-2 mg melanoaldehid/kg bahan pada ikan adalah batas nilai yang terjadinya perubahan bau yang signifikan. Angka TBA yang masih bisa diterima oleh panelis pada filet ikan mas hari ke-16 mencapai 0,46 mg melanoaldehid/ $/ \mathrm{kg}$ bahan. Besarnya kandungan TBA produk akan tergantung pada kandungan TBA awal sebagai raw material (Languardi 2011). Kandungan asam lemak bebas dan asam lemak tidak jenuh yang tinggi pada produk olahan ikan patin merupakan penyebab dari tingkat ketengikan yang tinggi. Kandungan asam lemak tidak jenuh, polyunsaturated fatty acid (PUFA) selain bermanfaat untuk kesehatan ternyata dapat mempermudah oksidasi lemak sehingga menyebabkan ketengikan (Syuryanti dan Suryaningrum 2009).

Penelitian selanjutnya adalah menentukan lama waktu penyimpanan bakso warna ikan lele ini mempunyai kadar TBA sama dengan atau lebih dari $0,123 \mathrm{mg}$ malonaldehid/kg sampel bk. Hasil uji TBA pada berbagai suhu dan lama waktu penyimpanan bakso warna ikan lele disajikan pada Tabel 3. 
Tabel 3. Angka TBA (mg malonaldehid/kg sampel bk) bakso warna ikan lele pada berbagai suhu *

\begin{tabular}{cccc}
\hline \multirow{2}{*}{ Waktu penyimpanan (hari) } & \multicolumn{3}{c}{ Angka TBA (mg malonaldehid/kg sampel bk) } \\
\cline { 2 - 4 } & $\mathbf{2 5}^{\circ} \mathbf{C}$ & $\mathbf{3 5}^{\circ} \mathbf{C}$ & $\mathbf{4 5}^{\circ} \mathbf{C}$ \\
\hline 0 & 0,020 & 0,034 & 0,026 \\
2 & 0,066 & 0,070 & 0,094 \\
4 & 0,085 & 0,092 & 0,150 \\
6 & 0,100 & 0,125 & 0,220 \\
8 & 0,126 & 0,206 & 0,340 \\
\hline
\end{tabular}

Data pada Tabel 3 menunjukkan bahwa semakin tinggi suhu, maka akan semakin tinggi nilai TBA. Pola reaksi pembentukan angka TBA bakso warna pada beberapa suhu penyimpanan diasumsikan berlangsung mengikuti pola reaksi kemunduran mutu orde nol (zero orde) karena diperoleh grafik yang linier seperti yang disajikan pada Gambar 1. Kenaikan angka TBA tersebut menunjukkan kenaikan kadar malonaldehid selama penyimpanan yang disebabkan adanya proses oksidasi. Proses oksidasi terjadi karena kontak antara oksigen dengan lemak yang menghasilkan asam lemak, kemudian peroksida dioksidasi lebih lanjut membentuk aldehid dalam bentuk malonaldehid sehingga nilai TBA meningkat (Fennema, 1976 di dalam Dewi 2004).

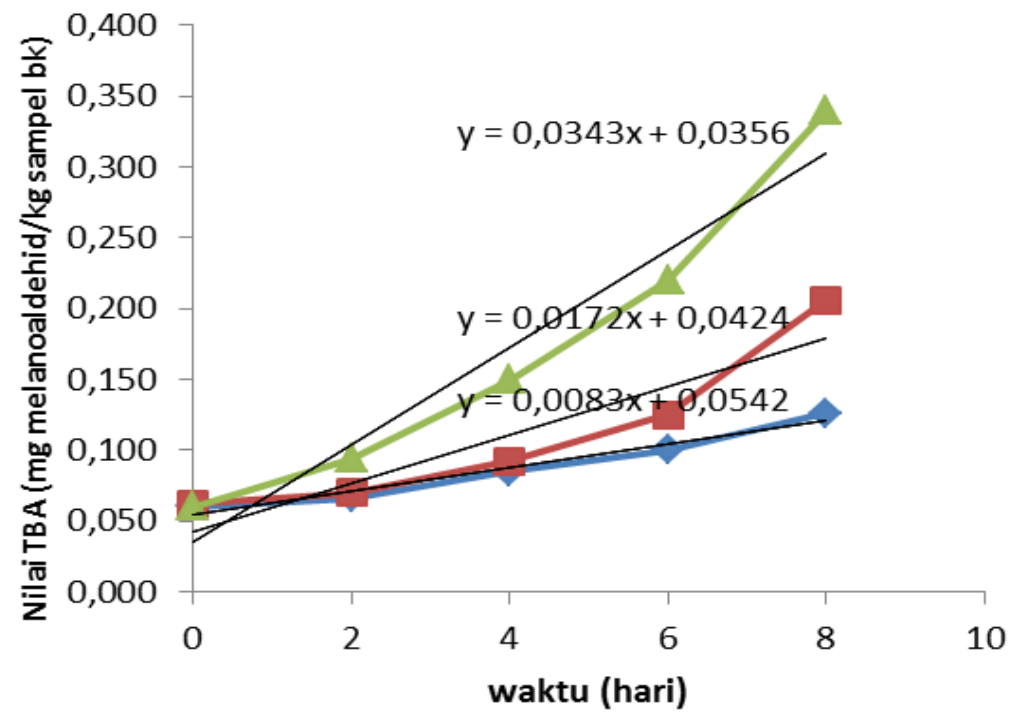

Keterangan: - suhu $25^{\circ} \mathrm{C},-$ suhu $35^{\circ} \mathrm{C},-$ suhu $45^{\circ} \mathrm{C}$

\section{Gambar 1. Grafik hubungan antara waktu penyimpanan dengan nilai TBA pada beberapa suhu penyimpanan}

Berdasarkan Gambar 1, dibuat Suhu $35^{\circ} \mathrm{C} y=0,0172 \mathrm{x}+0,0424(\mathrm{~K}=0,0172)$ persamaan regresi linier $Y=a+b X$ pada Suhu $25^{\circ} \mathrm{C} y=0,0083 x+0,0542(K=0,0083)$ masing masing suhu, yaitu:

Suhu $45^{\circ} \mathrm{C} y=0,0343 x+0,0356(K=$

Selanjutnya apabila nilai-nilai $K$ ini 0,0343 ) diterapkan dalam rumus Arrhenius, yaitu $\mathrm{K}=$ Ko.e-E/RT atau Ln $\mathrm{K}=\mathrm{Ln} \mathrm{Ko}-\mathrm{E} / \mathrm{RT}$, 
karena Ln ko dan -E/RT adalah konstanta, maka persamaan tersebut dapat ditulisak sebagai $L n K=A+B .1 / T$., sehingga apabila setiap nilai $K$ dan $1 / T$ diplotkan dalam sebuah grafik, maka akan diperoleh grafik seperti pada Gambar 2, diperoleh persamaan regresi linear yaitu $y=1994,6 x$ 9,6174. Persamaan tersebut digunakan untuk menentukan kinetika perubahan angka TBA bakso warna selama penyimpanan sebagai fungsi suhu. Energi aktivasi dihitung dari perkalian antara nilai kemiringan kurva (slope) dengan R. Nilai kemiringan kurva dari persamaan garis ini sebesar 1994,6 merupakan nilai E/R dari persamaan Arrhenius sedangkan $R$ (konstanta gas) sebesar 1,986 kal/moloK.

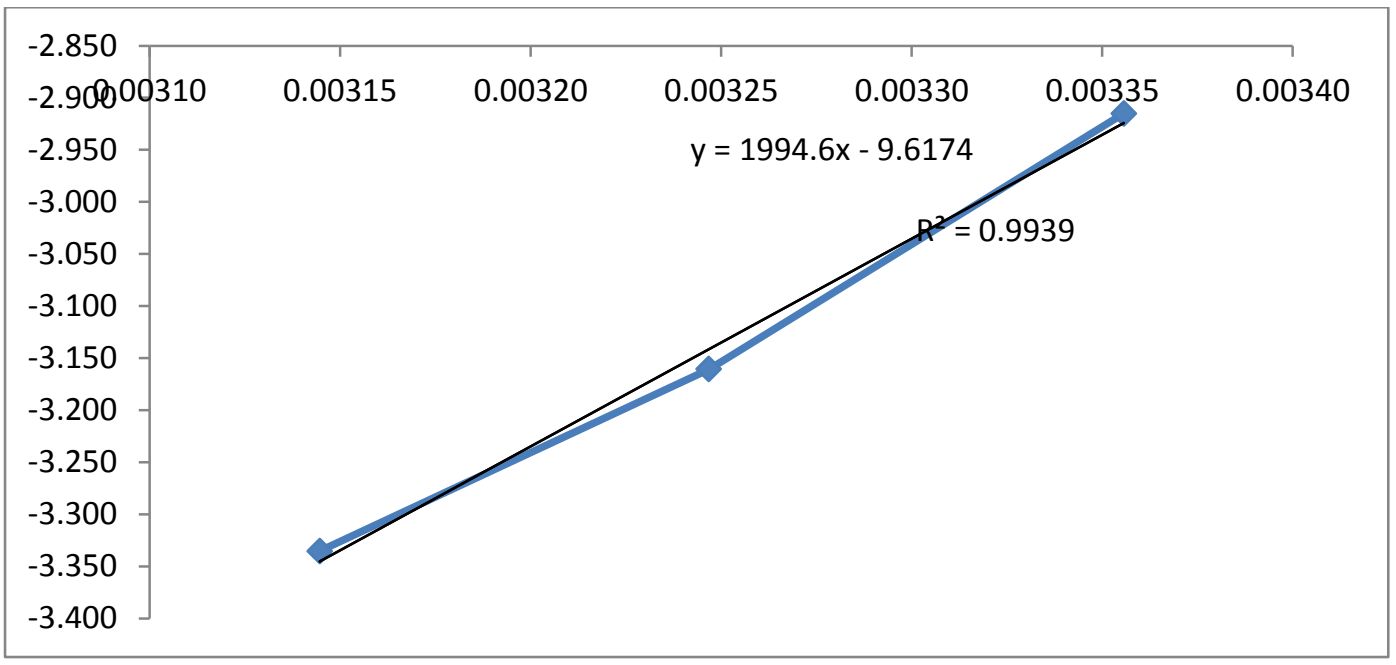

Gambar 2. Grafik hubungan antara suhu penyimpanan $\left(1 / \mathrm{T}^{\circ} \mathrm{K}\right)$ dengan $\ln \mathrm{k}$.

Nilai Q10 dapat dihitung dengan membagi laju penurunan mutu pada suhu +10 dengan suhu tertentu. Nilai Q10 bakso warna pada penyimpanan suhu 25 dan 35 ${ }^{\circ} \mathrm{C}$ adalah 1,2423 sedangkan nilai Q10 untuk suhu 35 dan $45^{\circ} \mathrm{C}$ sebesar 1,2251 . Nilai Q10 rata-rata 1,2333 . Nilai $\mathrm{Q} 10$ tersebut dapat digunakan untuk menentukan umur simpan seperti terlihat pada Tabel 4.

Tabel 4. Laju ketengikan dan penentuan nilai Q10

\begin{tabular}{ccc}
\hline Suhu $(\mathrm{K})$ & Laju ketengikan & Q10 \\
\hline 298 & $1,21 \times 10^{7}$ & \\
308 & $9,74 \times 10^{6}$ & 1,2423 \\
318 & $7,95 \times 10^{6}$ & 1,2251 \\
\hline
\end{tabular}

Penentuan umur simpan dapat ditentukan dengan rumus $T s=T s_{1} . Q 10^{\delta T / 10}$, maka rumus umur simpan bakso warna menjadi $\mathrm{Ts}=6 \times 1,2333^{\delta \mathrm{T} / 10}$. Dengan persamaan tersebut, maka dapat ditentukan umur simpan bakso warna dalam berbagai suhu. Jika bakso warna disimpan pada suhu chilling $5{ }^{\circ} \mathrm{C}$, maka umur simpan bakso warna menjadi 11,5 hari. Bakso ikan dari ikan Tilapia (Oreochromis mossambicus, Peters 1852) mengalami perubahan setelah disimpan selama 18 minggu dengan suhu penyimpanan $-20^{\circ} \mathrm{C}$ (Ninnan dkk 2012). Umur simpan dendeng ikan patin siam yang 
disimpan pada suhu ruang yaitu selama 22 hari, dan suhu $25^{\circ} \mathrm{C}$ selama 32 hari yang disimpan menggunakan plastik LDPE, dan metoda penentuan umur simpan metoda Arrhenius (Syuryanti 2009). Hot smoked catfish (Clarias gariepinus) yang disimpan pada suhu $4{ }^{\circ} \mathrm{C}$ menggunakan boks PVC mempunyai umur simpan 16 hari dengan metoda penentuan umur simpan secara konvensional (Yanar 2007). Pada produk Ready-To-Eat "Fish Peera" dari ikan anchovy (Stolephorous Commersoni) dalam kemasan Retort Pouches umur simpan produk adalah 1 tahun pada penyimpanan suhu $28 \pm 2{ }^{\circ} \mathrm{C}$ (Bindu dkk 2010).

\section{KESIMPULAN DAN SARAN}

Bakso warna ikan lele mengalami kemunduran mutu selama penyimpanan. Atribut mutu yang pertama kali berubah adalah bau yang identik dengan ketengikan atau senyawa thio barbituric acid (TBA) dengan nilai ambang ketengikan dalam TBA yaitu sebesar $0,123 \mathrm{mg}$ malonaldehid $/ \mathrm{kg}$ sampel bk. Umur simpan bakso warna jenis warna merah dapat ditentukan dengan menggunakan persamaan Ts= $6 \times 1,2333^{\delta / 110}$. Jika bakso warna tersebut disimpan pada suhu $5{ }^{\circ} \mathrm{C}$, maka umur simpannya adalah 11,5 hari.

Saran untuk penelitian selanjutnya adalah dilakukannya uji mikrobiologi selain uji organoleptis dan uji kimia untuk menentukan masa simpan produk.

\section{DAFTAR PUSTAKA}

Adebayo-Tayo BC, Odu NN, Igiwiloh NJPN, Okonko IO. 2012. Microbiological and Physicochemical Level of Fresh Catfish (Arius hendelotic) From Different Markets in Akwa lbom State, Nigeria. New York Science Journal, 2012;5(4)
Adoga IJ, Joseph E, Samuel OF. 2010. Studies on the Post-Mortem Changes in African Catfish (Clarias angullaris) During Ice -Storage. New York Science Journal 2010; 3(6) http://www. sciencepub.net

Marslandpress@gmail.com.

Arpah M, R Syarief. 2000. Evaluasi Modelmodel Pendugaan Umur Simpan Pangan dari Difusi Unidirectional Fick's Law. Bul. Teknol. Industri Pangan. Vol XI. No.1:11-16.

Azam K. SMN Alam. SS Naher. 2010. Quality assessment of farmed black tiger shrimp (Penaeus monodon) in supply chain: organoleptic evaluation. Journal Of Food Processing And Preservation 34 (2010) 164-175.

Bindu J. CN. Ravishankar, T.K. Srinivasa Gopal. A.K. Mallick. 2010. Investigation Of Shelf Life And Heat Penetration Attributes Of Ready-To-Eat "Fish Peera" From Anchovy (Stolephorous Commersoni) In Retort Pouches. Journal Of Food Processing And Preservation 34 (2010) 207-222.

Dewi IM, 2004. Sifat Kritis dan Umur Simpan Ukel Manis. Logika, Vol. 1, No. 2, Juli 2004, ISSN: 1410-2315.

Langroudi HF, M Soltani, A Kamali1, M R Ghomi, SE Hoseini, S Benjakul, Z Heshmatipour. 2011. Effect of Listeria monocytogenes inoculation, sodium acetate and nisin on microbiological and chemical quality of grass carp Ctenopharyngodon idella during refrigeration storage. African Journal of Biotechnology Vol. 10(42), pp. 84848490, 8 August, 2011 ISSN 16845315.

Meilgaard M, Civille GV, and Carr BT. 1999. Sensory Evaluation Techniques. 3rd ed. CRC Press, New York.

Ninnan G. J. Bindu And J. Joseph Frozen Storage Studies Of Value-Added 
Mince-Based Products From Tilapia (Oreochromis Mossambicus, Peters 1852). Journal Of Food Processing And Preservation 34 (2010) 255-271.

Sauza BWS, MA Cerqueira, HA Ruiz,JT Martins, A Caseariego, JA Teixeira, AA Vicente. 2010. Effect of ChitosanBased Coatings on the Shelf Life of Salmon (Salmo salar ). J. Agric. Food Chem. 2010, 58, 11456-11462

Syarief R dan Halid H. 1993. Teknologi Penyimpanan Pangan. IPB. 374pp.

Syuryanti, TD Suryaningrum. 2010. Pendugaan Umur Simpan Produk Hasil Perikanan. Squalen Buletin Pasca Panen dan Biotek kelautan dan Perikanan. Vol 5. No.1 hal 8-13.

Syuryanti. 2009. Kajian Sifat Fungsional Daging Lumat dan Surimi Ikan Patin Siam (Pangasius hypothalamus) dan Aplikasinya Menjadi Dendeng Serta Pendugaan Umur Simpannya. Thesis. Bogor: Program Pasca Sarjana, IPB.
Tsironi T. E Dhermesonlouoglou. M Ginnakuorou. P Taoukis. 2009. Shelf life modelling of frozen shrimp at variable temperature. Food Science and Technology. 42: 664-671.

Yanar Y. 2007. Quality Change of hot smoked catfish (Clarias Gariepinus) during refrigerated storage. Journal of Muscle Foods. 18; 391-400.

Yanar Y. M Celik. E Akamca. 2008. Effects of brine concentration on shelf-life of hot-smoked tilapia (Oreochromis niloticus) stored at $4{ }^{\circ} \mathrm{C}$. J. Food Chemistry Volume 97, Issue 2, July 2006, Pages 244-247

Yuniarti, An Yudhistira, H Suhrawardan. 2011. Pembuatan Bakso Ikan Lele (Clarias Sp.) Warna Warni Sebagai Alternatif Jajanan Anak Sekolah. $J$ Penyuluhan Perikanan dan Kelautan Vol 5. No. 1. ISSN 1978-6514. 